\title{
Buckling strength of adhesively-bonded single and double-strap repairson carbon-epoxy structures
}

\author{
R.D.S.G. Campilho, M.F.S.F. de Moura, D.A. Ramantani, J.J.L. Morais, J.J.M.S. Domingues
}

\begin{abstract}
AB STRACT

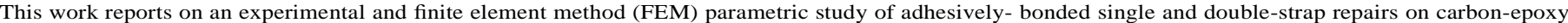

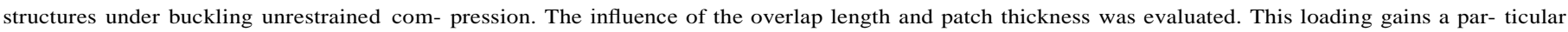

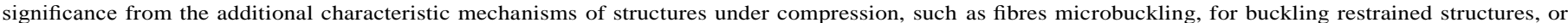

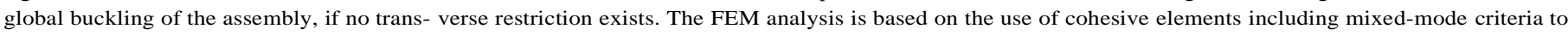

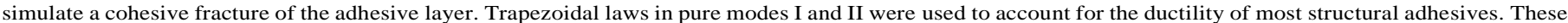

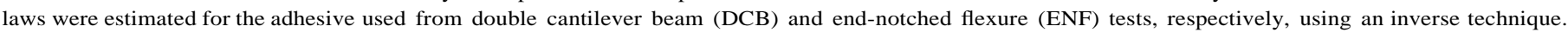

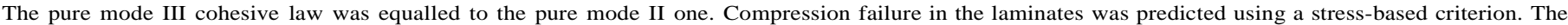

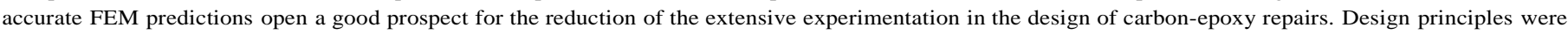
also established for these repairs under buckling.
\end{abstract}

Keywords: Laminate, Carbon fibres, Fracture, Finite element analysis (FEA) Cohesive zone model

\section{Introduction}

Carbon-fibre reinforced plastics (CFRP) have recently come to the fore owing to a set of interesting characteristics over conven- tional materials such as aluminium or steel. In fact, CFRP compos- ites are being increasingly used in structures requiring high specific strength and stiffness, such as in the automotive, marine, military, aeronautic and aerospace industries. The replacement costs of damaged CFRP components highlight the importance on the availability of effective repair procedures to restore their strength. Adhesively-bonded repairs overcome the limitations of the riveting or fastening approaches, such as the weight penalty or significant stress concentrations at localized regions, which can induce premature onset of damage. However, bonded assem- blies are more likely to fail under moderate fatigue stress levels [1,2]. The strap repair consists on drilling a hole to remove the damaged material, followed by adhesive-bonding of circular patches on one side (single strap, SS) or both sides (double strap, DS) of the laminate [3]. These repairs can be regarded as perma- nent in lightly loaded and relatively thin structures. However, they are not feasible for high responsibility structures, due to peel and shear stress concentrations at the bond edges, arising from the dif- ferential straining between the structure and patches along the bond length [3], which prevents a high efficiency.

Several authors addressed adhesively-bonded repair techniques for composite structures [4-14]. Numerically, the repairs strength can be predicted using stress or strain-based criteria for the adhe- sive layer, damaged structure and patch [15-20]. However, be- cause of the stress concentrations or singular regions typical of these repairs, the mentioned criteria are highly mesh dependent. Alternatively, cohesive zone models (CZM's) coupled to FEM simu- lations can be used [3,14,21-23], modelling damage growth in the adhesive layer and, in the case of layered fibre-reinforced compos- ites, also interlaminar, intralaminar or fibre fractures. This method- ology yields mesh independent results, since damage growth is ruled by energetic criteria. Additionally, accurate failure mecha- nisms predictions can be expected, provided that all fracture sce- narios are considered in the simulations. The DS repair technique on CFRP laminates under tension loads was studied by Liu and Wang [24]. An optimization study was carried out for the patch diameter, thickness and lay-up, as well as the adhesive thickness. The FEM simulations precisely estimated the repairs experimental strength, using the Tsai-Wu criterion to predict fibre and matrix 
cracking of the laminate and patches, the Ye delamination criterion to detect delamination between plies and the Maximum Shear Stress Criterion for the adhesive layer. The compressive behaviour of composite structures must also be considered in the design stages. In fact, different mechanisms arise under compression, such as fibres microbuckling, for buckling of restrained structures [25- 28], or global buckling of the assembly between clamping points, if no transverse restriction exists [29]. Fibres microbuckling comes from the compliant materials used as matrix, whilst global buck- ling is justified by the slenderness of elements, largely depending on their crosssection and elastic properties, in addition to the im- posed boundary and loading conditions. When loaded on its length direction, a slender member under unrestrained compression ini- tially deforms in pure compression. At a certain level of applied load, elastic instability of the beam leads to its transverse deflec- tion accompanied by crosssectional rotation around the axis of smaller second moment of inertia, which grows at an approximate constant load. This phenomenon is known as lateral buckling, and the corresponding load as the buckling load [29]. Owing to these mechanisms, fibre-reinforced laminates sustain smaller loads in compression than tension [30,31], implying that composite struc- tures under bending are more likely to fail in the compression re- gions. This also applies to repaired sandwich structures with composite faces, which would more easily fail in the compression face [32]. The accurate prediction of the stability limit states of CFRP repairs thus shows a particular importance, owing to the mentioned phenomena. This justified the attention paid to the development of theoretical and computational methods for the buckling analysis of slender elements, with emphasis on thin- walled composite panels [33,34]. With this purpose, analytical ap- proaches based on the Vlasov theory were applied to conventional

[35] and composite structures [36,37]. A few closed-form solutions were also developed for the buckling loads of slender structures [38-41]. Soutis et al. [42] performed a FEM analysis on the influ-

ence of several geometric parameters on the compressive strength of DS composite repairs, using a designed apparatus to prevent lateral buckling. The strength and locus of damage initiation of the repairs were estimated with the Maximum Normal Stress Criterion for the microbuckling in the laminate and the Average Shear Stress Criterion for the adhesive layer failure, giving accurate predictions.

The work of Finn et al. [43] concerns the behaviour of composite repairs under compression. The authors experimentally estimated the effectiveness of strap repairs on the compressive strength of CFRP laminates without global buckling restraining. It was found that the applied load increased until the buckling load, represent- ing the load at which the global buckling between grips initiated. A plateau region followed in the load-displacement $(P-\mathrm{d})$ curve, cor- responding to buckling, up to failure by extensive delamination.

Results indicated that for the damaged laminates used in the tests, no significant improvement of the compressive strength was attained. Therefore, the recommended course of action was not to execute the repair.

This work reports on an experimental and FEM parametric study of adhesively-bonded SS and DS repairs on CFRP laminates with a $\left[0_{2}, 90_{2}, 0_{2}, 90_{2}\right]$ s lay-up under buckling unrestrained com- pression. The influence of the overlap length $\left(L_{\mathrm{O}}\right)$ and patch thick- ness $\left(t_{\mathrm{H}}\right)$ was evaluated, which allowed the establishment of design principles for repairing of CFRP structures. The FEM analysis is based on the use of cohesive elements including mixed-mode cri- teria to simulate a cohesive fracture of the adhesive layer. Trape- zoidal tractionseparation laws in pure modes I and II were considered to reproduce the ductile characteristics of most struc- to the pure mode II one. Compression failure in the laminate emerging from the specimens buckling was predicted using a stress-based criterion.

\section{Cohesive zone model}

\subsection{Model description}

A mixed-mode $(\mathrm{I}+\mathrm{II}+\mathrm{III}) \mathrm{CZM}$ implemented within cohesive elements was used to simulate the elasto-plastic behaviour and fracture of an adhesive layer of Araldite 2015 with thickness $\left(t_{\mathrm{A}}\right)$ of $0.2 \mathrm{~mm}$. The cohesive elements are used in the numerical mod- els to connect the solid elements of ABAQUS simulating the lam- inate and patch, to reproduce the behaviour of the adhesive layer by using approximate traction-separation laws in each mode of loading. A trapezoidal law was considered for each pure mode to

relate stresses $\left(\mathrm{r}_{i}\right)$ and relative displacements $\left(\mathrm{d}_{i}\right)$ between homologous points of the cohesive elements with zero thickness (Fig. 1), to account for the adhesive ductility [44-46]. Actually, these adhe- sives are characterized by an approximate constant stress under plastic deformation, which can be approximated to the cohesive shape of Fig. 1. The homologous points of the cohesive elements correspond to the initially superimposed points of the cohesive elements in the numerical model, which are connected by the mixed-mode CZM of Fig. 1, following the established $r-d$ relationship up to failure. In general, structures are under mixed-mode. Therefore, the formulation includes a mixed-mode damage model, which is an extension of the pure-mode model (Fig. 1) and allows the simulation of the adhesive layer when under mixed-load con- ditions. Damage onset is predicted using the quadratic stress criterion

$$
\begin{aligned}
& \left(\frac{\sigma_{\mathrm{I}}}{\sigma_{\mathrm{II}}}\right)^{2}+\left(\frac{\sigma_{\mathrm{II}}}{\sigma_{\mathrm{III}}}\right)^{2}+\left(\frac{\sigma_{\mathrm{m}}}{\sigma_{\mathrm{mII}}}\right)^{2}=1 \text { if } \sigma_{1}>0 \\
& \left(\frac{\sigma_{\mathrm{II}}}{\sigma_{\mathrm{uII}}}\right)^{2}+\left(\frac{\sigma_{\mathrm{II}}}{\sigma_{\mathrm{uII}}}\right)^{2}=1 \quad \text { if } \sigma_{1} \leqslant 0
\end{aligned}
$$

where $\mathbf{r}_{i}\left(i=\mathrm{I}\right.$, II, III) represent the stresses in each mode and $\mathbf{r}_{\mathrm{u}, i}(\mathrm{I}$, II, III) the corresponding local strength. The first Eq. (1) can be rewritten as a function of the relative displacements

$$
\left(\frac{\delta_{1 \mathrm{~m}, \mathrm{I}}}{\delta_{1, \mathrm{I}}}\right)^{2}+\left(\frac{\delta_{\mathrm{Im, \textrm {I }}}}{\delta_{1, \mathrm{II}}}\right)^{2}+\left(\frac{\delta_{\mathrm{Im, \textrm {m }}}}{\delta_{1, \mathrm{II}}}\right)^{2}=1
$$

$\mathrm{d}_{1, i}(i=\mathrm{I}$, II, III) represent the pure mode relative displacements at damage initiation and $\mathrm{d}_{1 \mathrm{~m}, i}(i=\mathrm{I}$, II, III) the corresponding mixed-mode displacements. Stress softening onset was predicted using a criterion similar to (2)

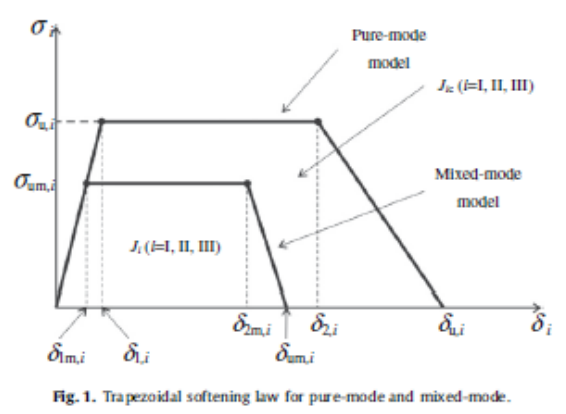


tural adhesives, such as the epoxy adhesive Araldite 2015 used in this work. The cohesive laws in pure modes I and II were estimated from DCB and ENF tests, respectively, using an inverse data fitting methodology. The pure mode III cohesive law was equalled 
Table 1

Cohesive parameters in pure modes I and II of a $t_{\mathrm{A}}=0.2 \mathrm{~mm}$ layer of Araldite 2015 .

\begin{tabular}{lllll}
\hline & $i$ & $J_{i c}(\mathrm{~N} / \mathrm{mm})$ & $\mathrm{r}_{\mathrm{u}, i}(\mathrm{MPa})$ & $\mathrm{d}_{2, i}(\mathrm{~mm})$ \\
\hline Pure mode & I & 0.43 & 23.0 & 0.01870 \\
& II & 4.70 & 22.8 & 0.1710 \\
\hline
\end{tabular}

$$
\left(\frac{\delta_{2 \mathrm{~m}, 1}}{\delta_{2,1}}\right)^{2}+\left(\frac{\delta_{2 \mathrm{~m}, \mathrm{II}}}{\delta_{2, \mathrm{II}}}\right)^{2}+\left(\frac{\delta_{2 \mathrm{~m}, \mathrm{~m}}}{\delta_{2, \mathrm{II}}}\right)^{2}=1 .
$$

mode crack propagation [21,53], oppositely to the characteristic pure mode I crack propagation in bulk adhesives.

\section{Numerical analysis}

The strap repair geometry is presented in Fig. 2. The character- istic dimensions of the repair are the laminate length $(a)$ and width $(b)$, the overlap length $\left(L_{0}\right)$, defined as the radial overlap between the hole and the patch, the laminate thickness $\left(t_{\mathrm{P}}\right)$, the adhesive layer thickness $\left(t_{\mathrm{A}}\right)$, the patch thickness $\left(t_{\mathrm{H}}\right)$ and the hole diameter

(d). It should be mentioned that $a$ denotes the specimens length between grips, while their total length is $150 \mathrm{~mm}$. A parametric analysis was performed, both experimentally and numerically, on the influence of $L_{\mathrm{O}}$ and $t_{\mathrm{H}}$ on the repairs behaviour, which will al- low the establishment of repair principles for these structures. The open-hole specimen (without patches) was also characterized, for

an evaluation of the strength improvement for the different repair configurations tested. The buckling behaviour of this notched configuration is extensively documented in the literature, due to its significance, for instance in bolted or riveted structures [27]. Moreover, the need for hole drilling can emerge in composite structures, further emphasizing the importance of the strength evaluation for this notched configuration. It is though emphasized the particular character of the quantitative predictions presented to the specific set of testing, material and dimensional conditions selected. Table 2 presents the geometries evaluated for the SS and DS repairs, and the patch lay-up for each value of $t_{\mathrm{H}}$. The $\left[0_{2}, 90_{2}, 0_{2}, 90_{2}\right]_{\mathrm{s}}$ lay-up was always used for the laminates. The label of the repairs defined in this table will be used throughout this work when addressing each one of the repair geometries mentioned, to simplify the nomenclature.

The numerical work was performed in ABAQUS ${ }^{\circledR}$, using geometric non-linearities due to the large deformations endured by the specimens under buckling, for a faithful representation of their behaviour [54]. Including the non-linear geometric effects is extre- mely important in the particular case of buckling compression, since a considerable lateral flexure is observed. Under these condi- tions, a linear geometric analysis would underestimate the repairs strength $[55,56]$. By the use of geometrical non-linearities, finite elements in the numerical simulations are always formulated in the current configuration using current nodal positions, with the update of the stiffness matrix of the structure on every increment. This is essential to guarantee an accurate representation of the real behaviour of the repairs tested, due to their transverse deflection before failure. Eight-node reduced integration solid finite elements were considered for the analysis, to keep the computational effort necessary to run the models at an acceptable level. These elements are compatible with the eight-node cohesive elements simulating the adhesive layer. Hexahedral eight-node and pentahedral six-

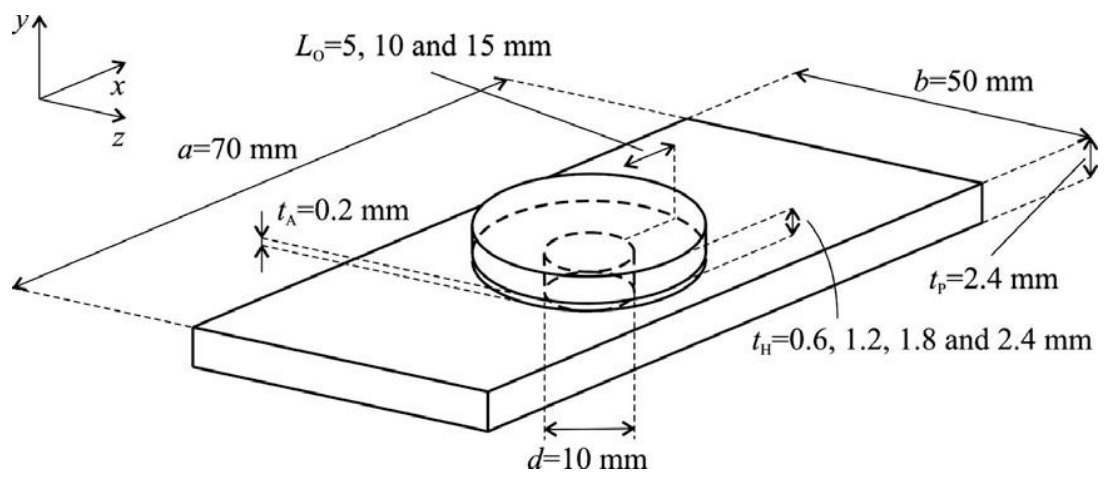


Fig. 2. SS repair geometry and dimensions. 
Table 2

Geometries evaluated for the SS and DS repairs.

\begin{tabular}{lcll} 
Label $(\mathrm{mm})$ & $L_{\mathrm{O}}(\mathrm{mm})$ & $t_{\mathrm{H}}(\mathrm{mm})$ & Patch lay-up \\
\hline$L_{\mathrm{O}}=5$ & 5 & 1.2 & {$\left[0_{2}, 90_{2}\right] \mathrm{s}$} \\
$L_{\mathrm{O}}=10$ & 10 & 1.2 & {$\left[0_{2}, 90_{2}\right] \mathrm{s}$} \\
$L_{\mathrm{O}}=15$ & 15 & 1.2 & {$\left[0_{2}, 90_{2}\right] \mathrm{s}$} \\
$t_{\mathrm{H}}=0.6$ & 10 & 0.6 & {$[0,90]_{\mathrm{s}}$} \\
$t_{\mathrm{H}}=1.2$ & 10 & 1.2 & {$\left[0_{2}, 90_{2}\right] \mathrm{s}$} \\
$t_{\mathrm{H}}=1.8$ & 10 & 1.8 & {$\left[0_{2}, 90_{2}, 0_{2}\right] \mathrm{s}$} \\
$t_{\mathrm{H}}=2.4$ & 10 & 2.4 & {$\left[0_{2}, 90_{2}, 0_{2}, 90_{2}\right] \mathrm{s}$} \\
\hline
\end{tabular}

node solid finite elements were employed in the simulations (Fig. 3 details the mesh at the repaired region for the $L_{O}=10 \mathrm{~mm}$ SS repair). The use of symmetry conditions at planes $A$ (transversal) and $B$ (longitudinal) allowed the consideration of only $1 / 4$ of the repair (Fig. 4). In all of the geometries, thirty elements were ap- plied along the overlap in the radial direction. The use of bias ef- fects towards the overlap edges guaranteed a refined mesh at these stress concentration regions [57,58]. Thirty elements were also used for ${ }^{1} 4$ of the patch in the circumferential direction. As a result, the cohesive elements for the simulation of the adhesive layer consisted of a layer of $30 \times 30$ elements. The meshes of the laminate and patch were built using one element through-thick- ness for each two adjacent equally oriented plies, except near the adhesive, where one element was used per ply because of the ex- pected stress concentrations. The four $90^{\circ}$ plies at the middle of the laminate were modelled using only one element through- thickness. Because of this mesh arrangement, the laminates of the SS repairs were modelled by eight plies of elements through- thickness (Fig. 3), whilst nine plies were considered for the lami- nate of the DS repairs, due to the additional ply of solid elements near the second adhesive layer. Each one of these eight or nine plies consisted of 1500 solid elements. By these principles, the patches were made of 3, 5, 7 or 9 plies of solid elements for the

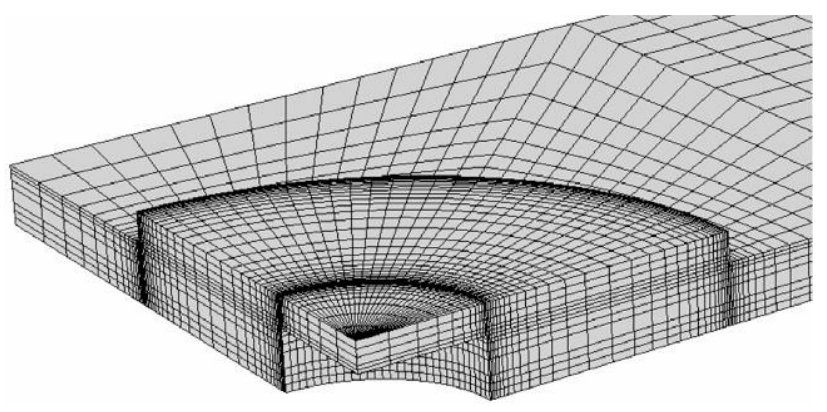

Fig. 3. Detail of the mesh at the overlap region $\left(L_{O}=10 \mathrm{~mm} \mathrm{SS}\right.$ repair $)$.

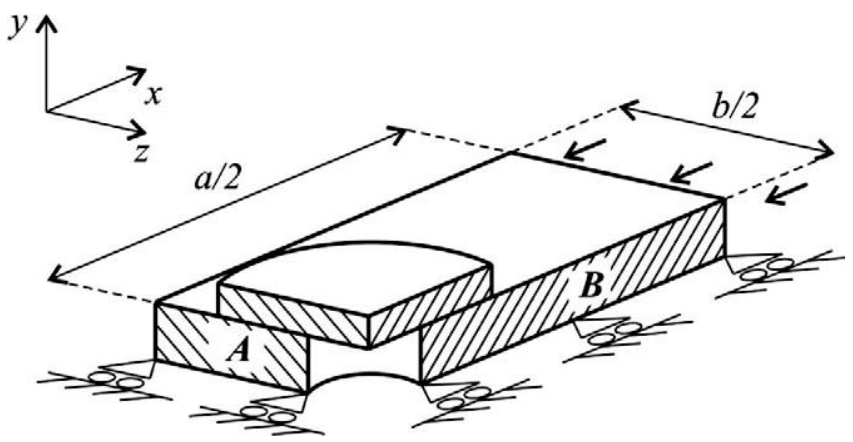

$t_{\mathrm{H}}=0.6$ to the $t_{\mathrm{H}}=2.4 \mathrm{~mm}$ patches, by the respective order, each of these plies consisting of 1200 solid elements. In view of this arrangement, the total number of elements ranged from 16,500 for the $t_{\mathrm{H}}=0.6 \mathrm{~mm}$ SS repair to 36,900 for the $t_{\mathrm{H}}=2.4 \mathrm{~mm} \mathrm{DS}$ re- pair. The CFRP laminates and patches were modelled as orthotropic elastic materials with the following properties for a unidirectional lamina (1fibres direction, 2-transverse direction, 3-thickness

direction): $E_{1}=109 \mathrm{GPa}, \quad E_{2}=E_{3}=8819 \mathrm{MPa}, \quad \mathrm{m}_{12}=\mathrm{m}_{13}=0.342$, $\mathrm{m}_{23}=0.380, G_{12}=G_{13}=4315 \mathrm{MPa}, G_{23}=3200 \mathrm{MPa}$ [3]. As previously mentioned, the cohesive fracture of the adhesive layer was evaluated by cohesive elements. Additionally, since the maximum load $\left(P_{\mathrm{m}}\right)$ for some of the tested conditions was ruled by a compression failure of the two superficial $0^{\circ}$ plies at the compression region of the laminates at plane $A$ (Fig. 4), a stress-based criterion was used to predict this occurrence $[24,42]$. This approach con- sisted on the experimental estimation of the average value of $\mathrm{d}$ leading to compression failure for the open-hole laminates. Follow-ing, with the corresponding FEM model, this value of $d$ was used to determine the average value of normal stress in the $x$ direction

$\left(\mathrm{r}_{\mathrm{x} \text { avg }}\right)$ in the two superficial $0^{\circ}$ plies at the compression region of the laminate at plane $A$ (Fig. 4). In the simulations of the repairs, the value of $r_{x}$ avg at the mentioned plies was used to assess compression failure. This course of action is substantiated by a practically simultaneous experimental failure at these two plies along the entire width of the specimens, even though it is known that longitudinal compressive stresses along the specimens' width are not constant, typically concentrating towards the hole edge. This implies that the failure stress obtained by the described inverse procedure cannot be regarded as independent of the repairs geom- etry, which is a disadvantage. A failure stress to be generically ap-plied to any repair geometry of the same composite material and lay-up can alternatively be obtained using a laminate without a notch, since under these conditions no stress concentrations are present for longitudinal compressive stresses along the width of the specimens.

\section{Experimental work}

The laminates and patches were fabricated by hand lay-up from unidirectional CFRP pre-preg with $0.15 \mathrm{~mm}$ of ply thickness (Texipreg HS $160 \mathrm{RM}$ from SEAL ), followed by curing in a hot-plates press at $130{ }^{\circ} \mathrm{C}$ and 2 bar during $1 \mathrm{~h}$. Cutting of the laminates from the bulk plates was achieved by a diamond coated disc saw. The $d=10$ $\mathrm{mm}$ holes were afterwards executed at in a conventional milling machine using solid carbide Guhring 1149 drills with a $10 \mathrm{~mm}$ diameter and an h8 tolerance. These drills were chosen due to their special application to fibre-reinforced materials. The circular patches were manufactured in a conventional turning lathe, using Cubic Boron Nitride inserts from SECO. The patches were also fabricated from bulk plates, initially cut in squares with slightly higher dimensions than the final patch diameter. At this stage, a straight line was marked in the patches, allowing for a sub- sequent correct alignment of the patches with the laminate. Machining of the patches in the turning lathe was carried out be- tween steel cylinders with the same diameter of the patches, firmly tightened between the lathe spindles. The bonding surfaces were abraded with 180 grit sandpaper and cleaned with acetone, to pre- vent adhesive failures [22,59]. To guarantee a uniform value of $t_{\mathrm{A}}$ over the entire bond area, a fishing line with a diameter of

$0.2 \mathrm{~mm}$ was used at four points at the edges between the patches and the laminates. The correct alignment of the patches lay-up was achieved using the straight line previously marked in the patches. To align the patch and certify the concentricity between the patch and the laminate hole, several markings were placed in the lami- nate. Following, measurements were performed with a digital 


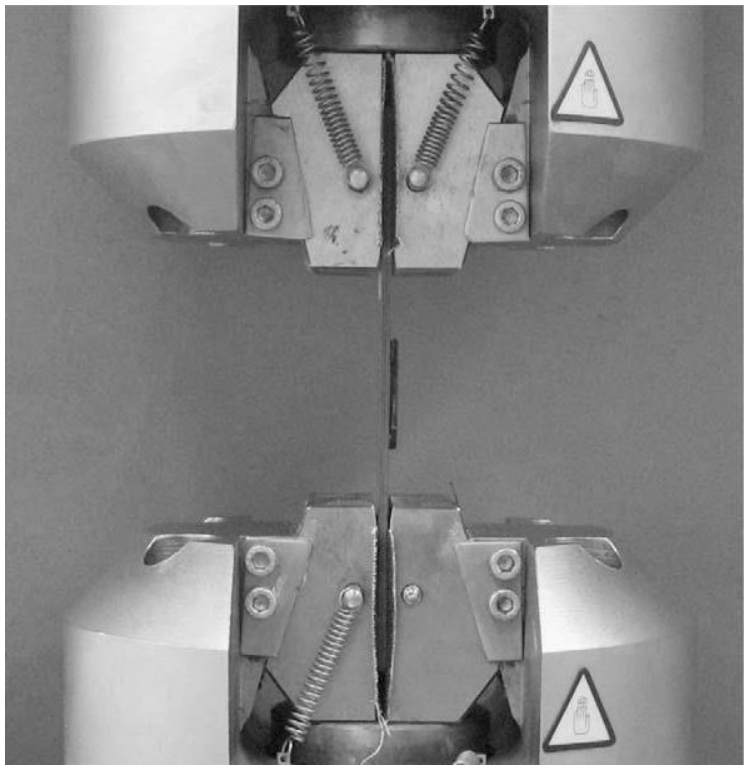

Fig. 5. Experimental setup in the testing machine ( $t_{\mathrm{H}}=2.4 \mathrm{~mm} \mathrm{SS}$ repair)

calliper after pressing of each patch with clamps. Curing of the adhesive was performed at room temperature. Before complete curing, the adhesive excess at the overlap edges was removed with a razor blade, to produce the geometry of Fig. 2. In all specimens, the adhesive excess at the hole was not removed. The repairs were tested in buckling unrestrained compression in a hydraulic testing machine (Instron 8801 ) equipped with a $100 \mathrm{kN}$ load cell, at a constant velocity of $0.5 \mathrm{~mm} / \mathrm{min}$ and at room temperature (Fig.5). This

equipment was chosen due to the robust grips fixing system, preventing any misalignment under load, which is essential for an accurate characterization of the repairs buckling characteristics.

Pictures were taken with $5 \mathrm{~s}$ intervals to fully characterize the damage evolution of the repairs up to failure and to perform a comparative analysis with the simulations. Three valid results were always assured for each test configuration.

\section{Results}

\subsection{Fracture mechanisms}

Analysis of the results and respective comparison between the experiments and numerical simulations are carried out in this sec- tion, beginning with the fracture characterization of the repairs up to failure. The global buckling and damage mechanisms identified during the tests are initially characterized:

- Global buckling: Corresponds to buckling between the testing machine grips. Fig. 6a shows an open-hole laminate under glo- bal buckling, with the indication of the laminate tension and compression faces. No evidence of damage was found under these conditions up to compression failure.

- Compression failure: Damage in the laminate face under compression, being characterized by a compressive fracture of the two superficial $0^{\circ}$ plies at plane $A$ (Fig. 4) along the entire spec- imens width, accompanied by a localized longitudinal matrix cracking at the hole edges [27]. Damage subsequently propa- gated to the adjacent plies, leading also to delaminations [31]. Fig. 6b, related to a $t_{\mathrm{H}}=2.4 \mathrm{~mm} \mathrm{SS}$ repair, pictures this damage mechanism.

- Laminate failure: Failure in the laminate outside the repair region, with no visible damage in the patches. An example of this fracture is shown in Fig. 6c, pertaining to a $L_{\mathrm{O}}=15 \mathrm{~mm}$ DS repair.

- Partial patch debonding: Localized cohesive fracture of the adhesive layer at the patch edge near plane $B$ (Fig. 4). Fig. 7a relates to a $t_{\mathrm{H}}=1.8 \mathrm{~mm}$ DS repair, while Fig. $7 \mathrm{~b}$ presents the respective detail.

- Patch debonding: Cohesive failure of the adhesive layer initiating at the patch edge near plane $B$ (Fig. 4) at one of the repair faces,

propagating to the entire bond. Fig. 7c represents a $L_{\mathrm{O}} \quad=10 \mathrm{~mm}$ DS repair after debonding of the two patches.

Tables 3 and 4 outline the experimental damage mechanisms ruling $P_{\mathrm{m}}$ as a function of $L_{\mathrm{O}}$ and $t_{\mathrm{H}}$ respectively. In some of the test conditions, designated by the dashed lines, damage occurred in two separate stages. However, $P_{\mathrm{m}}$ always corresponded to the first damage stage. The open-hole laminate failed by compression (Fig. 6a). For the majority of the repair geometries the value of $P_{\mathrm{m}}$ was related to patch debonding. The $L_{\mathrm{O}}=15 \mathrm{~mm} \mathrm{SS}$ and DS repairs and the $t_{\mathrm{H}}=0.6 \mathrm{~mm} \mathrm{SS}$ repair are the exception, with the value of $P_{\mathrm{m}}$ depending on the laminate strength. For the first ones, this can be explained in light of the larger adhesive shear area and consequent higher flexure capabilities of the patch before debonding than the repairs with smaller values of $L_{\mathrm{O}}$ [21,23]. Moreover, as the value of $L_{\mathrm{O}}$ increases, the inner region of the bond between the peak shear stresses at the overlap edges progressively becomes lightly stressed due to the differential straining of the laminate and patch along the overlap [3,22], which also helps to the reported modification of the failure mode. For the $t_{\mathrm{H}}=0.6 \mathrm{~mm}$
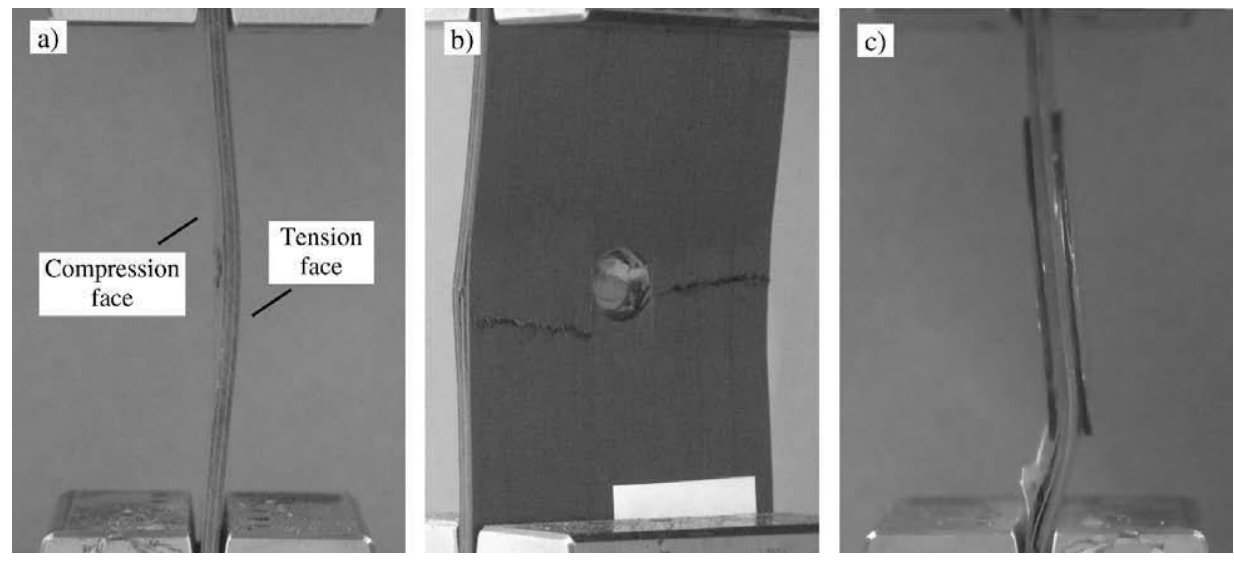

Fig. 6. Global bucking (a), laminate compression failure (b) and laminate failure outside the repair region (c). 

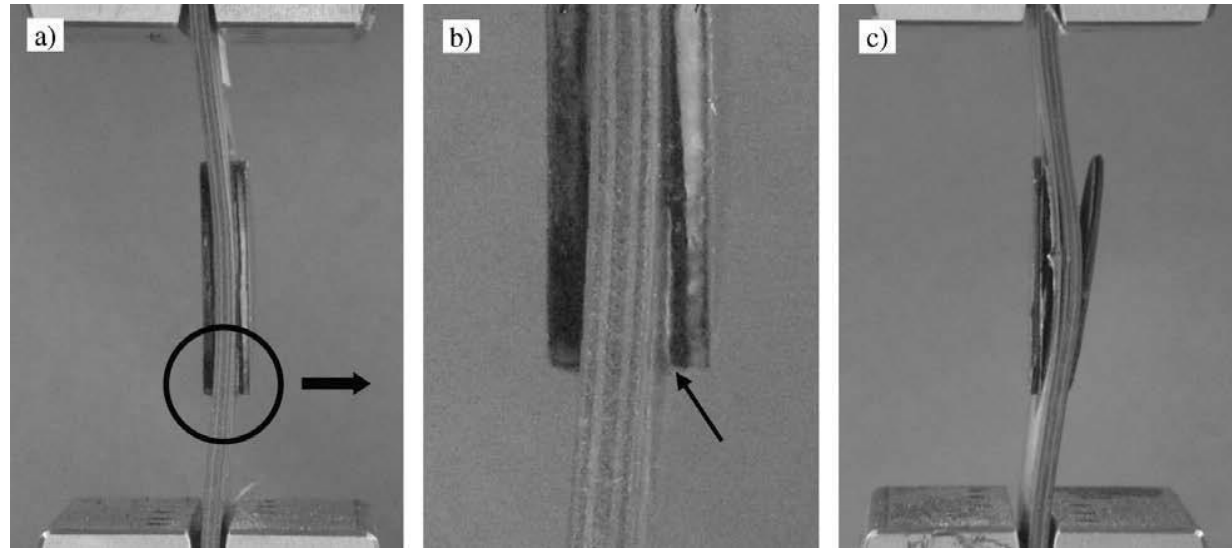

Fig. 7. Partial patch debonding (a), detail of the partial patch debonding (b) and patch debonding (c).

Table 3

Failure modes of the repairs as a function of $L_{\mathrm{O}}$.

\begin{tabular}{llll}
\hline Lo & $5 \mathrm{~mm}$ & $10 \mathrm{~mm}$ & $15 \mathrm{~mm}$ \\
\hline SS repairs & $\begin{array}{l}\text { Patch debonding } \\
\text { and compression } \\
\text { failure }\end{array}$ & $\begin{array}{l}\text { Patch debonding } \\
\text { and compression } \\
\text { failure }\end{array}$ & Compression failure \\
DS repairs & $\begin{array}{l}\text { Patch debonding } \\
\text { and compression } \\
\text { failure }\end{array}$ & $\begin{array}{l}\text { Partial patch } \\
\text { debonding }\end{array}$ & $\begin{array}{l}\text { Patch debonding } \\
\text { outside the repair } \\
\text { region }\end{array}$ \\
& $\begin{array}{l}\text { Patch debonding } \\
\text { and compression } \\
\text { failure }\end{array}$ & \\
\hline
\end{tabular}

Table 4

Failure modes of the repairs as a function of $t_{\mathrm{H}}$

\begin{tabular}{|c|c|c|c|c|}
\hline$t_{\mathrm{H}}$ & $0.6 \mathrm{~mm}$ & $1.2 \mathrm{~mm}$ & $1.8 \mathrm{~mm}$ & $2.4 \mathrm{~mm}$ \\
\hline \multirow[t]{2}{*}{ SS repairs } & $\begin{array}{l}\text { Compression } \\
\text { failure }\end{array}$ & $\begin{array}{l}\text { Patch debonding } \\
\text { and compression } \\
\text { failure }\end{array}$ & $\begin{array}{l}\text { Patch } \\
\text { debonding } \\
\text { and compression } \\
\text { failure }\end{array}$ & $\begin{array}{l}\text { Partial patch } \\
\text { debonding }\end{array}$ \\
\hline & & & & $\begin{array}{l}\text { Patch } \\
\text { debonding } \\
\text { and } \\
\text { compression } \\
\text { failure }\end{array}$ \\
\hline DS repairs & $\begin{array}{l}\text { Partial patch } \\
\text { debonding } \\
\text { Compression } \\
\text { failure }\end{array}$ & $\begin{array}{l}\text { Partial patch } \\
\text { debonding } \\
\text { Patch } \\
\text { debonding } \\
\text { and } \\
\text { compression } \\
\text { failure }\end{array}$ & $\begin{array}{l}\text { Partial patch } \\
\text { debonding } \\
\text { Patch } \\
\text { debonding } \\
\text { and compression } \\
\text { failure }\end{array}$ & $\begin{array}{l}\text { Partial patch } \\
\text { debonding } \\
\text { Patch } \\
\text { debonding } \\
\text { and } \\
\text { compression } \\
\text { failure }\end{array}$ \\
\hline
\end{tabular}

SS repair, this behaviour is due to the bigger patch flexibility, lead- ing to smaller magnitude of through-thickness peel and shear peak stresses in the adhesive layer [47]. For the remaining repair geometries, as previously mentioned, failure was related to patch debonding which, compared to these exceptions, can be substanti- ated by the smaller resistant area of the adhesive or smaller allow- able flexibility of the patches owing to their bigger values of $t_{\mathrm{H}}$, leading to a premature cohesive failure of the adhesive compared to the compressive failure of the laminate.

In the following, an experimental/numerical cooperative study is performed for a few of the configurations tested. It should be firstly noticed that an increasing deviation of stiffness with $d$ was noticed for all repairs between the experiments and numerical simulations. This was caused by a minor slipping of the repairs in the testing machine grips, leading to an experimental reduction of stiffness during the tests that is not representative of the real behaviour of the composite. The analysis begins with the $L_{\mathrm{O}}$ $=15 \mathrm{~mm}$ and $t_{\mathrm{H}}=2.4 \mathrm{~mm}$ SS repairs. Fig. 8 corresponds to the numerical patch debonding. For the $L_{\mathrm{O}}=15 \mathrm{~mm}$ SS repairs (Fig. 8a), the patch debonded after $r_{\mathrm{x} \text { avg }}$, while for the $t_{\mathrm{H}}=2.4 \mathrm{~mm}$ SS repair (Fig. 8b) the opposite scenario occurred. Fig. 9a shows the $P$ d curves for the $L_{\mathrm{O}}=15 \mathrm{~mm} \mathrm{SS}$ repairs, with the value of $P_{\mathrm{m}}$ being related to compression failure (Table 3, Fig. 6b). This causes the minor drop on $P_{\mathrm{m}}$ observed in the experimental $P-\mathrm{d}$ curves at $\mathrm{d}$ $0.60 \mathrm{~mm}$. The subsequent drops of $P$ relate to patch debonding and compression failure at plane $A$ (Fig. 4). Consistently to these results, the abrupt drop of $P$ on the numerical curve at $\mathrm{d} \gg 0.80 \mathrm{~mm}$ was related to patch debonding, after the predicted compression failure and $P_{\mathrm{m}}$ (the circle marks in the numerical $P-\mathrm{d}$ curves corre- spond to the compression failure prediction). For the $t_{\mathrm{H}}=2.4 \mathrm{~mm} \mathrm{SS}$ repairs (Fig. $9 \mathrm{~b}$ ), the experimental drop on $P_{\mathrm{m}}$ is due to partial

patch debonding (Table 4, Fig. 7a and b). A small plateau followed, prior to final failure by complete patch debonding (Fig. 7c) and compression failure of the laminate (Fig. 6b). This behaviour was equally captured by the FEM simulation. In fact, patch debonding (corresponding to the drop on $P_{\mathrm{m}}$ at $\mathrm{d} \diamond 0.55 \mathrm{~mm}$ ) took place prior to $\mathbf{r}_{\mathrm{x} \text { avg. }}$. The fracture predictions for the other configurations were also in close agreement with the test results.

The corresponding DS repairs (i.e., $L_{\mathrm{O}}=15 \mathrm{~mm}$ and $t_{\mathrm{H}}=2.4 \mathrm{~mm}$ ) are also addressed in this discussion. Considering the $L_{O}=15 \mathrm{~mm}$ DS repair (Fig. 10a), the drop on $P_{\mathrm{m}}$ of the experimental $P-\mathrm{d}$ curves occurs due to laminate failure outside the repair region (Table 3 ,

Fig. 6c). The numerical approximation shows a value of $P_{\mathrm{m}}$ of identical magnitude, and compression failure in the laminate occurring after this value. Patch debonding occurs only after $(\mathrm{d}>0.82 \mathrm{~mm}$ ), which is consistent with the experiments. However, it should be mentioned that only in this particular case the proposed stress criterion is not the most adequate, since the laminate failure occurred mostly by delamination between differently oriented plies (Fig. 6c) instead of compression failure (Fig. 6b). For the $t_{\mathrm{H}}=2.4 \mathrm{~mm}$ DS repair (Fig. 10b), $P_{\mathrm{m}}$ was ruled by the repair buckling (Fig. 6a). A partial patch debonding event (Table 4, Fig. 7a and b) and a very small plateau region followed, prior to complete failure by patch debond- ing (Fig. 7c) and compression failure (Fig. 6b). This behaviour was obtained numerically, with $P_{\mathrm{m}}$ related to the onset of global buckling and the abrupt drop at $\mathrm{d} \gg 0.60 \mathrm{~mm}$ corresponding to partial patch debonding followed by compression failure shortly after. The estimated compression failure occurs only after $P_{\mathrm{m}}$ and patch debonding, which is consistent with the experimental observations. 

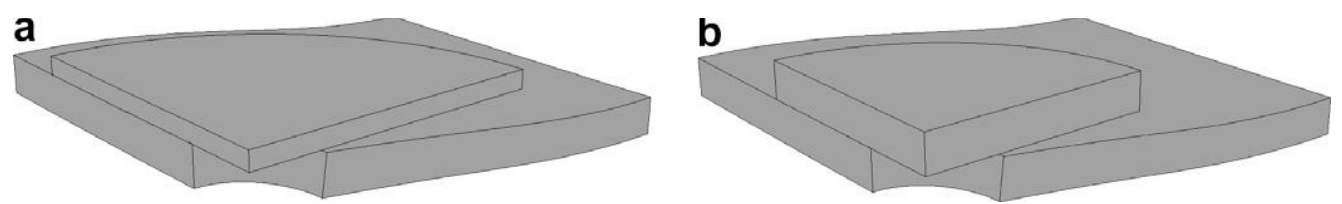

Fig. 8. Numerical models for the $L_{\mathrm{O}}=15 \mathrm{~mm}$ (a) and $t_{\mathrm{H}}=2.4 \mathrm{~mm}$ (b) SS repairs after patch debonding near the longitudinal symmetry plane (plane $B$ ).
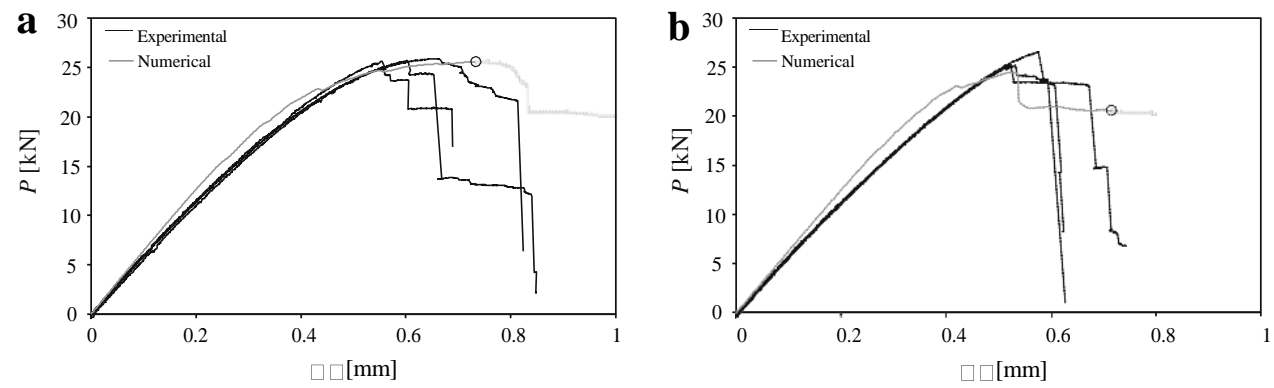

Fig. 9. Comparison between the experimental and numerical $P-\mathrm{d}$ curves for the $L_{\mathrm{O}}=15 \mathrm{~mm}$ (a) and $t_{\mathrm{H}}=2.4 \mathrm{~mm}$ (b) SS repairs.
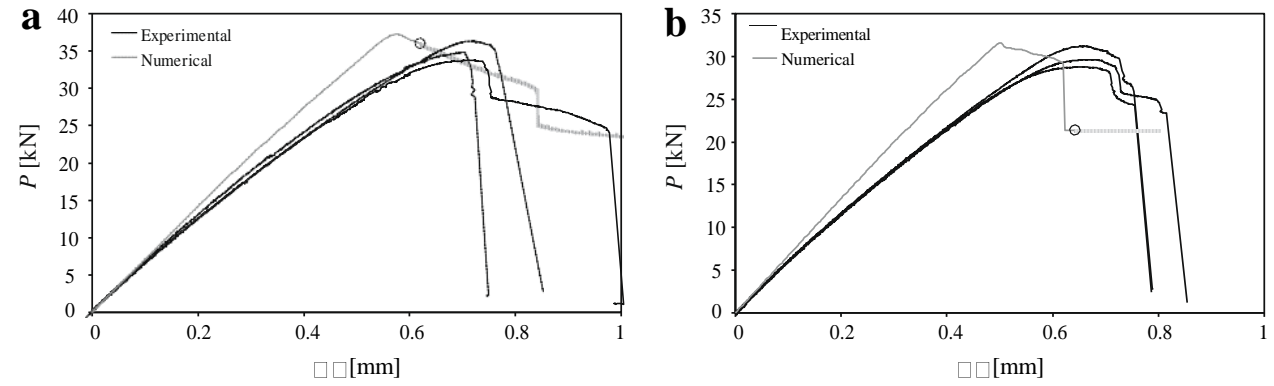

Fig. 10. Comparison between the experimental and numerical $P-\mathrm{d}$ curves for the $L_{\mathrm{O}}=15 \mathrm{~mm}$ (a) and $t_{\mathrm{H}}=2.4 \mathrm{~mm}$ (b) DS repairs.

\subsection{Summary of the results}

A comparative analysis is performed between the experimental and numerical results of elastic stiffness $(K$; Fig. 11$)$ and $P_{\mathrm{m}}$ (Fig. 12) as a function of $L_{\mathrm{O}}$ and $t_{\mathrm{H}}$, including the standard deviation of the experiments. $K$ is defined as the $P /$ d quotient in the initial part of the $P-\mathrm{d}$ curve. The predictions of $K$ were accurate as a function of both quantities. The gradual increase of $K$ with $L_{\mathrm{O}}$ (Fig. 11a) for both SS and DS repairs is explained in light of the progressive increase of the adhesive shear area and corresponding larger reinforcement capabilities of the patches [21,23]. This also applies to the difference between the SS and DS repairs. On the other hand, $t_{\mathrm{H}}$ only affects $K$ up to $1.8 \mathrm{~mm}$ for both SS and DS repairs (Fig. $11 \mathrm{~b}$ ). An identical trend between $P_{\mathrm{m}}$ and $K$ could be expected under these circumstances, since the value of $P_{\mathrm{m}}$ for structures under pure compression typically corresponds to the initiation of global buckling, which is determined by their stiffness [60,61]. The char- acteristic dimensions of structures are also known to greatly influ- a 75

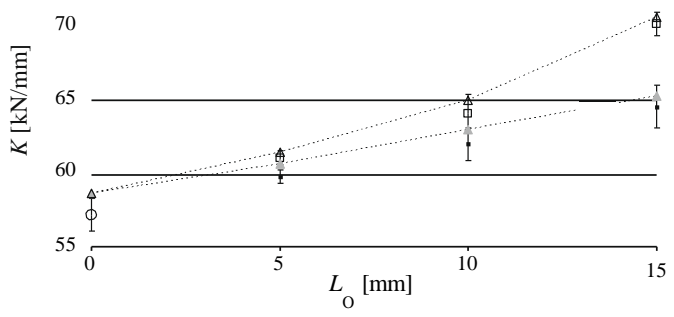

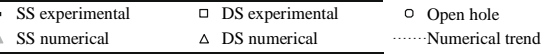

b 75

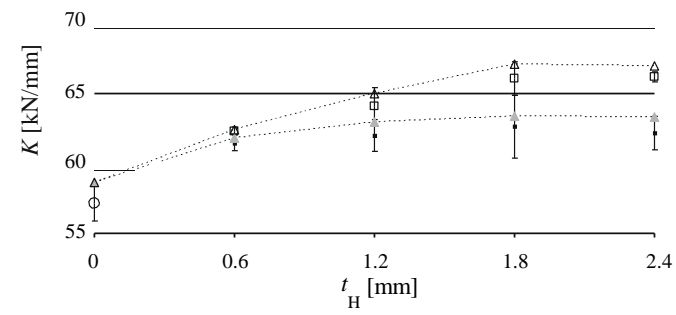

\begin{tabular}{lll}
\hline$\cdot$ SS experimental & $\square$ DS experimental & $\circ$ Open hole \\
$\Delta$ SS numerical & $\Delta$ DS numerical & $\cdots \cdots$ Numerical trend \\
\hline
\end{tabular}

Fig. 11. $K$ as a function of $L_{\mathrm{O}}$ (a) and $K$ as a function of $t_{\mathrm{H}}$ (b). 


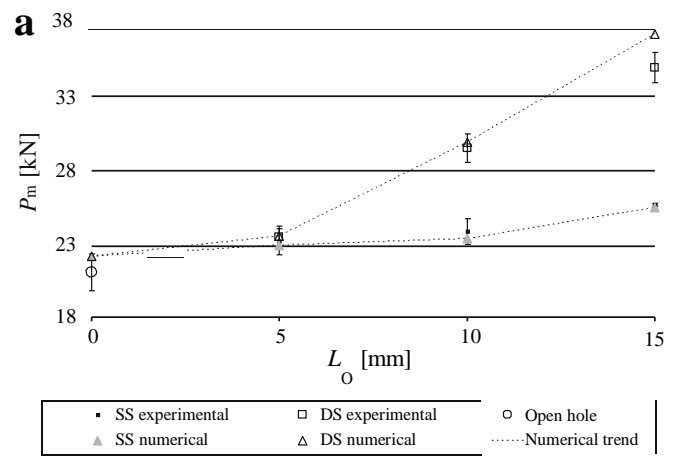

b 38

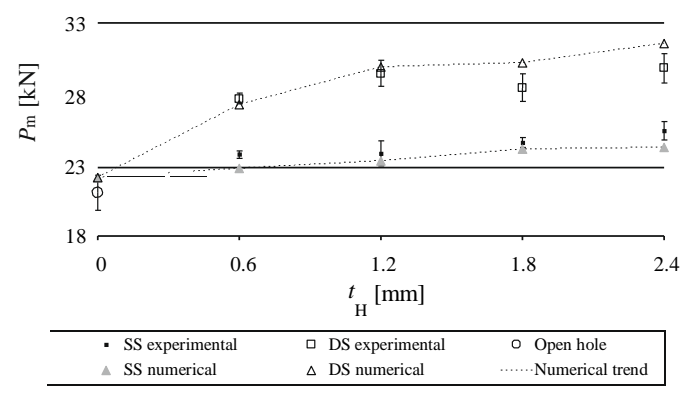

Fig. 12. $P_{\mathrm{m}}$ as a function of $L_{\mathrm{O}}$ (a) and $P_{\mathrm{m}}$ as a function of $t_{\mathrm{H}}(\mathrm{b})$.

ence $P_{\mathrm{m}}$. In fact, Eryigit et al. [29] reported on the buckling loads of thin glass-epoxy laminates with a circular hole at different locations, among which equally to this work, i.e., at the middle of the laminate. For this geometry, the buckling load significantly diminished by increasing the length between grips. A moderate reduction was also found by increasing the hole diameter. Oppositely, the strength of the materials involved typically only influences the failure displacement. However, in this particular situation, the prospect of premature patch debonding and compression fail- ure, prior to global buckling, must be investigated. Actually, some of the tested geometries showed a premature patch debonding be- fore global buckling (Tables 3 and 4), of which the $t_{\mathrm{H}}=2.4 \mathrm{~mm}$ SS repairs are an example (Fig. 9b). On the other hand, the $L_{O}=15 \mathrm{~mm}$ SS repairs failed by compression prior to global buckling (Fig. 9a). Apart from these exceptions, on all the other repair geometries

$P_{\mathrm{m}}$ was ruled by the value of $K$, and a plateau on the $P-\mathrm{d}$ curves was observed prior to the initiation of damage. Based on these assumptions, the tendencies between $K$ and $P_{\mathrm{m}}$ showed some similarities. In fact, $P_{\mathrm{m}}$ increased with $L_{\mathrm{O}}$ for the SS and DS repairs, with an increasing difference between both with $L_{\mathrm{O}}$. It should be emphasized that the numerical prediction for the $L_{O}=15 \mathrm{~mm}$ DS repair corresponds to a criterion (compression failure in the laminate, Fig. $6 \mathrm{~b})$ that was not consistent with the experimental failure mode mentioned earlier (laminate failure outside the repair region, Fig. 6c). Fig. 12a) also emphasizes on the major difference of $P_{\mathrm{m}}$ be- tween the SS and DS repairs. Even though with both repair config- urations the strengthening at the notch region increases gradually with $L_{\mathrm{O}}$ (thus having in both cases a strength improvement of $P_{\mathrm{m}}$ with $L_{\mathrm{O}}$ ), the improvement of $P_{\mathrm{m}}$ is much more significant for the DS repairs. This is due to the load eccentricity that exists with the SS repair geometry notwithstanding the value of $L_{\mathrm{O}}$, and is pre- vented using DS repairs $[3,10]$. This eccentric load, which increases with $L_{O}$ due to the corresponding increase of adhesive shear area [42], helps to the lateral flexure of the laminates with correspond- ing smaller strength improvement.

The value of $t_{\mathrm{H}}$ showed a bigger influence on $P_{\mathrm{m}}$ for the smaller values of $t_{\mathrm{H}}$. A significant and similar difference was also found between the SS and DS repairs for all the values of $t_{\mathrm{H}}$. Overall, the FEM predictions were accurate. In terms of basic principles for repairing composite structures under buckling compression, for the range of $L_{\mathrm{O}}$ and $t_{\mathrm{H}}$ values examined, the $L_{\mathrm{O}}=15 \mathrm{~mm}$ DS repairs showed to be the most effective. An acceptable restitution of strength was also attained using DS repairs with $L_{\mathrm{O}}=10 \mathrm{~mm}$ and $1.2<t_{\mathrm{H}}<2.4 \mathrm{~mm}$, and also with $L_{\mathrm{O}}=15 \mathrm{~mm}$ SS repairs. However, these particular results shall be considered valid only for the set of material, geometrical and testing conditions selected for this study, since the buckling behaviour of these structures is extremely sensitive to is- sues such as the materials stiffness in the loading direction, load eccentricity and specimen length between grips, amongst other parameters [43]. As a result, when in the presence of different conditions, the repairs should be numerically analysed and optimized prior to their execution.

\section{Concluding remarks}

An experimental and finite element parametric study was performed on the behaviour of single and double-strap repairs of car- bonepoxy laminates under buckling unrestrained compression. The influence of the overlap length and patch thickness on the fail- ure modes, elastic stiffness and strength of the repairs was evalu- ated, to validate a finite element methodology to simulate adhesively-bonded assemblies. This procedure used a trapezoidal mixed-mode cohesive zone model to simulate the adhesive layer and a stress-based criterion to predict compression failure in the laminate. The cohesive laws of the adhesive layer in pure modes I and II were estimated by an inverse method. The pure mode III cohesive law was equalled to the pure mode II one. Results showed that the finite element method can be a valuable predictive tool and an option for the reduction of costs due to experimentation, provided that suitable criteria are employed for the simulation of the different types of fracture. Design principles were proposed to execute single and double-strap repairs on composite structures under compression, which should not be separated from the spe- cific set of conditions selected for the repairs. For the range of over- lap length $(5-15 \mathrm{~mm})$ and patch thickness values examined $\quad(0.6-$

$2.4 \mathrm{~mm}$ ), the $15 \mathrm{~mm}$ overlap length double-strap repairs showed the best results. Good results were also attained using double-strap repairs with $10 \mathrm{~mm}$ of overlap length and values of patch thickness between 1.2 and $2.4 \mathrm{~mm}$, and also with single-strap repairs with an overlap length of $15 \mathrm{~mm}$.

\section{Acknowledgements}

The authors would like to thank the Portuguese Foundation for Science and Technology for supporting the work here presented, through the individual Grant SFRH/BD/30305/2006 and the re- search project PDTC/EME-PME/64839/2006.

\section{References}

[1] Renton WJ, Vinson JR. The efficient design of adhesive bonded joints. J Adhesion 1975;7:175-93.

[2] Renton WJ, Vinson JR. Fatigue behaviour of bonded joints in composite material structures. J Aircraft 1975;12:442-7.

[3] Campilho RDSG, de Moura MFSF, Domingues JJMS. Modelling single and double-lap repairs on composite materials. Compos Sci Technol 2005;65:194858.

[4] Myhre SH, Beck CE. Repair concepts for advanced composite structures. J Aircraft 1979;16:720-8. 
[5] Deaton JW. Repair of advanced composites commercial aircraft structures. Eng Mater Handbook, vol. 3. ASM Int.; 1987. p. 829-39.

[6] Hall SR, Raizenne MD, Simpson DL. A proposed composites repair methodology for primary structure. Composites 1988;20:479-83.

[7] Ong CL, Shen SB. Repair of F-104 aircraft nosedome by composite patching. Theor Appl Fract Mech 1991;15:75-83.

[8] Ahn SH, Springer GS. Repair of composite laminates-I: test results. J Compos Mater 1998;32:1036-74.

[9] Ahn SH, Springer GS. Repair of composite laminates-II: models. J Compos Mater 1998;32:1076-114.

[10] Hu FZ, Soutis C. Strength prediction of patch repaired CFRP laminates loaded in compression. Compos Sci Technol 2000;60:1103-14.

[11] Chu WS, Ahn SH. Internet-based composite repair. J Compos Mater 2006;39:82745.

[12] Campilho RDSG, de Moura MFSF, Domingues JJMS. Stress and failure analyses of scarf repaired CFRP laminates using a cohesive damage model. J Adhes Sc Technol 2007;21:855-970.

[13] Campilho RDSG, de Moura MFSF, Pinto AMG, Morais JJL, Domingues JJMS. Modelling the tensile fracture behaviour of CFRP scarf repairs. Compos Part B Eng 2009;40:149-57.

[14] Campilho RDSG, de Moura MFSF, Domingues JJMS. Numerical prediction on the tensile residual strength of repaired CFRP under different geometric changes. Int J Adhes Adhes 2009;29:195-205.

[15] Bigwood DA, Crocombe AD. Non-linear adhesive bonded joint design analyses. Int $\mathbf{J}$ Adhes Adhes 1990;10:31-41.

[16] Ikegami K, Takeshita T, Matsuo K, Sugibayashi T. Strength of adhesively bonded scarf joints between glass fibre-reinforced plastics and metal. Int J Adhes Adhes 1990;10:199-206.

[17] Harris JA, Adams RD. Strength prediction of bonded single-lap joints by nonlinear finite element methods. Int J Adhes Adhes 1984;4:65-78.

[18] Lee SJ, Lee GL. Development of a failure model for the adhesively bonded tubular single lap joint. J Adhesion 1992;40:1-14

[19] Papanikos P, Tserpes KI, Labeas G, Pantelakis S. Progressive damage modelling of bonded composite repairs. Theor Appl Fract Mech 2005;43: 189-98.

[20] Hua Y, Crocombe AD, Wahab MA, Ashcroft IA. Modelling environmental degradation in EA9321-bonded joints using a progressive damage failure model. J Adhesion 2006;82:135-60.

[21] Campilho RDSG. Modelação da Execução de Reparações em Materiais Compósitos. M.Sc. Thesis. Faculty of Engineering of Porto University, Portugal; 2005.

[22] Campilho RDSG, de Moura MFSF, Domingues JJMS. Using a cohesive damage model to predict the tensile behaviour of CFRP single-strap repairs. Int J Solids Struct 2008;45:1497-512.

[23] Campilho RDSG, de Moura MFSF, Domingues JJMS, Morais JJL. Computational modelling of the residual strength of repaired composite laminates using a cohesive damage model. J Adhes Sci Technol 2008;22:1565-91.

[24] Liu X, Wang G. Progressive failure analysis of bonded composite repairs. Compos Struct 2007;81:331-40

[25] Lessard LB, Chang FK. Effect of load distribution on fiber buckling strength of unidirectional composites. J Compos Mater 1991;25:65-87.

[26] Lankford J. The compressive failure of polymeric composites under hydrostatic confinement. Compos Part A - Appl Sci 1997;28:409-18

[27] Lee J, Soutis C. Measuring the notched compressive strength of composite laminates: specimen size effects. Compos Sci Technol 2008;68: 2359-66.

[28] Berbinau P, Soutis C, Guzl IA. Compressive failure of $0^{\circ}$ unidirectional carbon fiber-reinforced plastic (CFRP) laminates by fiber microbuckling. Compos Sci Technol 1999;59:1451-5.

[29] Eryigit E, Zor M, Arman Y. Hole effects on lateral buckling of laminated cantilever beams. Compos Part B - Eng 2009;40:174-9.

[30] Tsuji N, Kubomura K. Non-linear compression stress-strain curve of pitch- based high modulus carbon fibre composites and structural responses. J Mater Sci $1992 ; 27: 3782-8$.

[31] Suemasu H, Takahashi H, Ishikawa T. On failure mechanisms of composite laminates with an open hole subjected to compressive load. Compos Sci Technol 2006;66:634-41.

[32] Ramantani DA, Campilho RDSG, de Moura MFSF, Marques AT. Stress and failure analysis of repaired sandwich composite beams using a cohesive damage model J Sandw Struct Mater. doi: 10.1177/1099636208104520.
[33] Svensson SE. Lateral buckling of beams analyzed as elastically supported columns subject to a varying axial force. J Constr Steel Res 1985;5:179-93.

[34] Haengsoo L, Dong-Won J, Jin-Ho J, Seyoung I. Finite element analysis of lateral buckling for beam structures. Comput Struct 1994;53:1357-71.

[35] Wang CM, Wang CY, Reddy JN. Exact solutions for buckling of structural members. Boca Raton: CRC Press; 2004

[36] Lee J, Kim SE, Hong K. Lateral buckling of I-section composite beams. Eng Struct 2002;24:955-64.

[37] Sapkas A, Kollar LP. Lateral-torsional buckling of composite beams. Int J Solids Struct 2002;39:2939-63.

[38] Anderson JM, Trahair NS. Stability of monosymmetric beams and cantilevers. ASCE J Struct Div 1972;98:269-86.

[39] Pi YL, Trahair NS. Prebuckling deflections and lateral buckling II: Applications. ASCE J Struct Eng 1992;118:2967-85.

[40] Trahair NS. Flexural-torsional buckling of structures. Boca Raton: CRC Press; 1993.

[41] Mohri F, Azrar L, Potier-Ferry M. Lateral post-buckling analysis of thin-walled open sections beams. Thin-Walled Struct 2002;40:1013-36.

[42] Soutis C, Duan DM, Goutas P. Compressive behaviour of CFRP laminates repaired with adhesively bonded external repairs. Compos Struct 1999;45:289-301.

[43] Finn SR, He YF, Springer GS, Lee HJ. Compressive strength of damaged and repaired composite plates. J Compos Mater 1992;26:1796-825.

[44] Andersson T, Stigh U. The stress-elongation relation for an adhesive layer loaded in peel using equilibrium of energetic forces. Int J Solids Struct 2004;41:413-34.

[45] Hogberg JL, Stigh U. Specimen proposals for mixed mode testing of adhesive layer. Eng Fract Mech 2006;73:2541-56.

[46] Leffler K, Alfredsson KS, Stigh U. Shear behaviour of adhesive layers. Int J Solids Struct $2007 ; 44: 530-45$.

[47] Campilho RDSG, de Moura MFSF, Ramantani DA, Morais JJL, Domingues JJMS. Tensile behaviour of three-dimensional carbon-epoxy adhesively-bonded single and double-strap repairs. Int J Adhes Adhes 2009;29:678-86.

[48] Marques EAS, da Silva LFM. Joint strength optimization of adhesively bonded patches. J Adhesion 2008;84:917-36.

[49] de Moura MFSF, Gonçalves JPM, Chousal JAG, Campilho RDSG. Cohesive and continuum mixed-mode damage models applied to the simulation of the mechanical behaviour of bonded joints. Int J Adhes Adhes 2008;28:419-26.

[50] de Moura MFSF, Campilho RDSG, Gonçalves JPM. Crack equivalent concept applied to the fracture characterization of bonded joints under pure mode I loading. Compos Sci Technol 2008;68:2224-30.

[51] de Moura MFSF, Campilho RDSG, Gonçalves JPM. Pure mode II fracture characterization of composite bonded joints. Int J Solids Struct 2009;46:1589-95.

[52] Pardoen T, Ferracin T, Landis CM, Delannay F. Constraint effects in adhesive joint fracture. J Mech Phys Solids 2005;53:1951-83.

[53] Gonçalves JPM, de Moura MFSF, Magalhães AG, de Castro PMST. Application of interface finite elements to three-dimensional progressive failure analysis of adhesive joints. Fatigue Fract Eng M 2003;26:479-86.

[54] Osnes H, Andersen A. Computational analysis of geometric nonlinear effects in adhesively bonded single lap joints. Compos Part B - Eng 2003;34:417-27.

[55] Tsai MY, Morton J. The effect of a spew fillet on adhesive stress distributions in laminated composite single-lap joints. Compos Struct 1995;32:123-31.

[56] Mortensen F, Thomsen OT. Analysis of adhesive bonded joints: a unified approach Compos Sci Technol 2002;62:1011-31.

[57] da Silva LFM, Adams RD. Adhesive joints at high and low temperatures using similar and dissimilar adherends and dual adhesives. Int $\mathbf{J}$ Adhes Adhes 2007; $27: 216-26$

[58] Radice J, Vinson J. On the use of quasi-dynamic modeling for composite material structures: analysis of adhesively bonded joints with midplane asymmetry and transverse shear deformation. Compos Sci Technol 2006;66:2528-47.

[59] Zimmerman K, Liu D. Geometrical parameters in composite repair. J Compos Mater 1995;29:1473-87.

[60] Helms JE, Li G, Pang SS. Buckling analysis of a taper-taper adhesive-bonded composite joint. Polym Compos 2003;24:45-52.

[61] Timoshenko SP, Gere JM. Theory of elastic stability. New York: McGraw-Hill; 1961. 